\title{
Insufficient $\beta$-lactam concentrations in the early phase of severe sepsis and septic shock
}

\author{
Fabio Silvio Taccone1, Pierre-François Laterre², Thierry Dugernier ${ }^{3}$, Herbert Spapen ${ }^{4}$, Isabelle Delattre ${ }^{5}$, \\ Xavier Wittebole², Daniel De Backer ${ }^{1}$, Brice Layeux ${ }^{6}$, Pierre Wallemacq ${ }^{5}$, Jean-Louis Vincent ${ }^{1}$ and Frédérique Jacobs ${ }^{* 6}$
}

\begin{abstract}
Introduction: Altered pharmacokinetics (PK) in critically ill patients can result in insufficient serum $\beta$-lactam concentrations when standard dosages are administered. Previous studies on $\beta$-lactam PK have generally excluded the most severely ill patients, or were conducted during the steady-state period of treatment. The aim of our study was to determine whether the first dose of piperacillin-tazobactam, ceftazidime, cefepime, and meropenem would result in adequate serum drug concentrations in patients with severe sepsis and septic shock.
\end{abstract}

Methods: Open, prospective, multicenter study in four Belgian intensive care units. All consecutive patients with a diagnosis of severe sepsis or septic shock, in whom treatment with the study drugs was indicated, were included. Serum concentrations of the antibiotics were determined by high-pressure liquid chromatography (HPLC) before and $1,1.5,4.5$ and 6 or 8 hours after administration.

Results: 80 patients were treated with piperacillin-tazobactam $(n=27)$, ceftazidime $(n=18)$, cefepime $(n=19)$ or meropenem $(n=16)$. Serum concentrations remained above 4 times the minimal inhibitory concentration $(T>4 \times$ MIC), corresponding to the clinical breakpoint for Pseudomonas aeruginosa defined by the European Committee on Antimicrobial Susceptibility Testing (EUCAST), for $57 \%$ of the dosage interval for meropenem (target MIC $=8 \mu \mathrm{g} / \mathrm{mL}$ ), $45 \%$ for ceftazidime ( $\mathrm{MIC}=32 \mu \mathrm{g} / \mathrm{mL}$ ), 34\% for cefepime $(\mathrm{MIC}=32 \mu \mathrm{g} / \mathrm{mL}$ ), and $33 \%$ for piperacillin-tazobactam (MIC $=$ $64 \mathrm{\mu g} / \mathrm{mL}$ ). The number of patients who attained the target PK profile was 12/16 for meropenem (75\%), 5/18 for ceftazidime (28\%), 3/19 (16\%) for cefepime, and 12/27 (44\%) for piperacillin-tazobactam.

Conclusions: Serum concentrations of the antibiotic after the first dose were acceptable only for meropenem. Standard dosage regimens for piperacillin-tazobactam, ceftazidime and cefepime may, therefore, be insufficient to empirically cover less susceptible pathogens in the early phase of severe sepsis and septic shock.

\section{Introduction}

Severe sepsis and septic shock remain a major cause of morbidity and mortality in medical and surgical ICUs [1]. Although early and appropriate antibacterial therapy is considered a priority in the management of patients with sepsis $[2,3]$, there is evidence that optimizing antibiotic dosage regimens to achieve therapeutic concentrations in the blood and at the site of infection is equally important [4].

Antibiotherapy in critically ill septic patients usually consists of a broad-spectrum $\beta$-lactam combined with a glycopeptide and/or an aminoglycoside [5]. These drugs

* Correspondence: fjacobs@ulb.ac.be

${ }^{6}$ Department of Infectious Diseases, Erasme Hospital, Université Libre de Bruxelles, route de Lennik 808, 1070 Bruxelles, Belgium

Full list of author information is available at the end of the article cover a large variety of pathogens and can be empirically used for Gram-negative bacterial infections, including those caused by Pseudomonas aeruginosa. The activity of $\beta$-lactams is predominantly time-dependent and requires serum and tissue antibiotic concentrations above the minimal inhibitory concentration (MIC) of the pathogen to achieve adequate bacterial killing [6]. This effect is independent of peak levels and there is no significant post-antibiotic effect, except for carbapenems. Clinical data suggest that maximum killing of bacteria occurs when serum concentrations are maintained above the MIC of the causative pathogens for extended periods $[7,8]$; this may be especially appropriate in patients with compromised host-defences, including critically ill patients $[9,10]$. However, in conventional bolus dosing 
regimens, serum $\beta$-lactam concentrations may fall to low levels between doses $[11,12]$, with potentially negative effects on clinical response and emergence of resistances.

Antibiotic dosage regimens used in ICU patients are often based on pharmacokinetic (PK) data that were obtained in healthy volunteers or less severely ill patients. Moreover, they rarely take into account the dynamic changes of the septic process that can reduce the efficacy of anti-infective treatments and consequently affect patient outcomes [6]. During severe sepsis and septic shock, increased volume of distribution (Vd) and cardiac output can reduce serum drug concentrations, whereas decreased protein binding and end-organ dysfunction induce higher antibiotic levels [13]. Optimizing antibiotic dosage strategy should involve PK parameters, but therapeutic drug monitoring is necessary in septic patients because large inter-individual PK variations make it difficult to predict antibiotic levels [14]. As previous PK studies on $\beta$-lactams in ICU patients have excluded the most severely ill patients or were conducted in the steady-state period of treatment [15-17], the main objective of this study was to determine whether the currently recommended first dose of four broad-spectrum $\beta$-lactams (piperacillin-tazobactam, ceftazidime, cefepime, and meropenem) provide adequate plasma concentrations in critically ill septic patients in the ICU. We also tried to determine whether clinical or hemodynamic parameters could affect the PK profile of these drugs during such severe infections.

\section{Materials and methods}

\section{Study design, patients, antibiotic treatment and data} collection

This was a prospective, multicenter, observational study performed in four Departments of Intensive Care in Belgium (at the St-Luc Hospital, Erasme Hospital, and UZVUB in Brussels and St Pierre Hospital in Ottignies). The study protocol was approved by the university ethics committees of the different hospitals. Before enrolment, written consent was obtained from the patient or their nearest relative.

All patients admitted to one of the four ICUs between January 2005 and July 2006 were considered for inclusion. Inclusion criteria were a diagnosis of severe sepsis or septic shock [18], either at admission or during the ICU stay, and treatment with a broad-spectrum $\beta$-lactam antibiotic (ceftazidime, cefepime, piperacillin-tazobactam, or meropenem). Patients meeting one of the following criteria were excluded: age less than 18 years or more than 85 years; pregnancy or lactation; previous administration of any of the investigated antibiotics; chronic renal failure requiring dialysis; or allergy to any of the investigated antibiotics. The study period was limited to the first 24 hours of antibiotherapy.
Administration of the four $\beta$-lactams was made according to local guidelines. These drugs are generally used in the participating centers to treat hospital- or ICUacquired infections or in the case of community-acquired infection when a more-resistant pathogen may be involved (recent hospitalization or antibiotic therapy, previous colonization by more resistant strain). Piperacillin-tazobactam was preferred as first-line therapy in cases of proven or suspected intra-abdominal infections. Ceftazidime and cefepime was used as first-line therapy in other cases. Meropenem was used as second-line therapy (i.e. failure of piperacillin-tazobactam or cephalosporins) or in case of suspected or previous colonization by extended spectrum beta-lactamase Gram-negative bacteria.

In all study patients, demographics, pre-existing chronic diseases, admission diagnosis and biological data were collected in institutional databases. The severity of illness of each patient was characterized using the Acute Physiology and Chronic Health Evaluation (APACHE) II [19] and sequential organ failure assessment (SOFA) [20] scores determined on the first day of antibiotic treatment. Creatinine clearance $(\mathrm{CrCl})$ was calculated using a standard formula [21]. Treatment of patients with catecholamines, mechanical ventilation, hemofiltration or hemodialysis was recorded, as was length of ICU and hospital stay, overall mortality, and cause of death. Hemodynamic data were collected at baseline, and 8 and 24 hours after the start of the protocol.

\section{Analytic method for $\beta$-lactams}

All the patients included in the study received a first dose of $2 \mathrm{~g}$ ceftazidime or cefepime, $4 \mathrm{~g} / 0.5 \mathrm{~g}$ piperacillintazobactam, or $1 \mathrm{~g}$ meropenem. The usual daily doses of these antibiotics and dose adjustments for renal function are presented in Additional file 1. All the patients also received amikacin and the two antibiotics were administered simultaneously over 30 minutes using an infusion pump. Blood samples of $5 \mathrm{~mL}$ were collected without anticoagulant immediately before the infusion (0 hour) and $1,1.5,4.5$, and 6 or 8 hours (depending on the frequency of administration of the $\beta$-lactam) thereafter; these blood-draw time points were chosen as they belong to the elimination phase of all four antibiotics. The exact sampling time was recorded by the nursing or medical staff. Blood samples were centrifuged at $4000 \mathrm{~g}$ for 10 minutes after blood clotting. To allow for possible drug instability at room temperature, serum samples were stored at $-80^{\circ} \mathrm{C}$ until analysis.

All antibiotic quantitative analyses were performed in a centralized reference laboratory (St Luc Hospital). Importantly, as the PK of piperacillin and tazobactam are highly correlated [22], we only measured piperacillin levels. Serum $\beta$-lactam concentrations were determined by 
high-performance liquid chromatography with diode array detection. The intravenous antibiotic formulations were reconstituted according to the manufacturers' recommendations and diluted in water in order to reach stock solution aliquots of $1 \mathrm{mg} / \mathrm{mL}$, stored at $-20^{\circ} \mathrm{C}$. Before each assay, a fresh calibration curve was prepared from the stock solution and blank serum at the following concentrations: $0.75,1,2,5,10,25$, and $50 \mu \mathrm{g} / \mathrm{mL}$ for piperacillin-tazobactam; $5,10,25,50$, and $100 \mu \mathrm{g} / \mathrm{mL}$ for ceftazidime; $0.1,0.25,0.5,1,5,10,25$, and $50 \mu \mathrm{g} / \mathrm{mL}$ for cefepime or meropenem. The calibration and liquid-liquid extraction procedures as well as chromatographic conditions have been described previously [23]. The validation of the four analytical methods was performed over a three-day period with five calibration curves per day (i.e., 15 serum samples per concentration level). All methods were validated according to the published acceptance criteria for specificity, linearity, accuracy, precision (intra-day (repeatability), inter-day (intermediate precision)) and sensitivity (limit of detection (LOD) and limit of quantification (LOQ)). Specificity was determined by the ability to identify the $\beta$-lactam from its characteristic retention time and ultraviolet spectrum, and the fine resolution of its chromatographic peak. The linearity of the calibration curve was demonstrated by a significant linear regression analysis, with a determination coefficient $\left(\mathrm{r}^{2}\right)$ more than 0.99. Accuracy was expressed as the percent deviation of the mean observed concentration from the theoretical value, which should not exceed $15 \%$, except at the LOQ (20\%). Precision was acceptable if the intra- and inter-day coefficients of variation $(\mathrm{CV})$ were $20 \%$ or less at the LOQ and $15 \%$ or less at all other concentrations. LOQ was defined as the lowest concentration of the calibration curve, which could be reliably differentiated from background noise with a signal-to-noise ratio of at least 10:1 and quantified with acceptable accuracy (80 to $120 \%$ ) and precision $(\mathrm{CV} \leq 20 \%)$; LOD was defined as the lowest concentration that could be detected and reliably differentiated from background noise with a signal-to-noise ratio of at least 3:1.

The carry-over effect was tested by injecting regular blank samples and ultrapure water into the high-performance liquid chromatography system after high concentration calibrators. Under the described chromatographic conditions, piperacillin-tazobactam, ceftazidime, cefepime, and meropenem were identified by sharp and well-resolved peaks. The linearity was statistically confirmed over the concentration range tested for each $\beta$ lactam and was associated with an $\mathrm{r}^{2}$ of more than 0.999 . The four analytical methods were accurate and precise. LOD and LOQ were 0.50 and $0.75 \mu \mathrm{g} / \mathrm{mL}$, respectively, for piperacillin-tazobactam, 2.00 and $5.00 \mu \mathrm{g} / \mathrm{mL}$ for ceftazidime, and 0.07 and $0.10 \mu \mathrm{g} / \mathrm{mL}$ for cefepime and meropenem. Appropriate dilution was performed for clinical samples with concentrations above the upper analytic range (corresponding to the calibration curve).

\section{PK analysis}

The PK of the four antibiotics was individually assessed using WinNonlin Professional version 5.0.1. software (Pharsight Corporation, Mountain View, CA, USA). A one-compartment model with first-order elimination was selected to fit the data. Investigated PK parameters included maximal serum concentration (Cmax, calculated by extrapolation of the elimination phase at the end of the infusion) $\mathrm{Vd}$, total clearance (CL), elimination halflive $\left(t_{1 / 2}\right)$ and area under the serum concentration-time curve (AUC). Vd and CL were normalized to the body weight.

\section{PK end-points}

The threshold of MIC required for maximal $\beta$-lactam activity is still controversial. In this study, the adequacy of $\beta$-lactam therapy was assessed by calculating the time spent greater than four times the target MIC $(\mathrm{T}>4 \times$ $\mathrm{MIC}$ ). For each drug, the optimal T $>4 \times$ MIC was considered as: above $50 \%$ for piperacillin-tazobactam, above $70 \%$ for ceftazidime and cefepime, and above $40 \%$ for meropenem in Gram-negative bacterial infections [24]. As the dosage interval of $\beta$-lactams is prolonged in renal impairment [see Additional file 1], we calculated the time before the subsequent administration according to the adjustment of the drug regimen to $\mathrm{CrCl}$ for each patient. As there is a large variance in MIC values for different bacteria, we considered the MICs for problematic pathogens, such as $P$. aeruginosa, commonly isolated in ICU patients, as the empiric target threshold [25]. Sensitivity thresholds of MIC for this pathogen, as defined by European Committee on Antimicrobial Susceptibility Testing (EUCAST), are: $8 \mu \mathrm{g} / \mathrm{mL}$ or less (ceftazidime, cefepime), $16 \mu \mathrm{g} / \mathrm{mL}$ or less (piperacillin-tazobactam), and $2 \mu \mathrm{g} / \mathrm{mL}$ or less (meropenem) [see Additional file 1] [26]. We, therefore, classified each patient as having an 'adequate' or 'inadequate' PK profile according to the percentage of time during which serum drug concentrations remained more than four times the clinical breakpoint for P. aeruginosa (\% T > $4 \times \mathrm{MIC}$ ): $32 \mu \mathrm{g} / \mathrm{mL}$ or more (ceftazidime, cefepime), $64 \mu \mathrm{g} / \mathrm{mL}$ or more (piperacillin-tazobactam), and $8 \mu \mathrm{g} / \mathrm{mL}$ or more (meropenem). Finally, by simulation using the PK parameters of our population, we calculated the probability of achieving target $\mathrm{T}>4 \times \mathrm{MIC}$ values for other MICs that can be found in ICU-isolated Gram-negative bacteria.

\section{Statistical analysis}

Statistical analyses were performed using the SPSS 13.0 for Windows NT software package (SPSS Inc. 2004, Chi- 
cago, IL, USA). Descriptive statistics were computed for all study variables. A Kolmogorov-Smirnov test was used, and histograms and normal-quantile plots were examined to verify the normality of distribution of continuous variables. Discrete variables were expressed as counts (percentage) and continuous variables as means \pm standard deviation or median (25th to 75th percentiles). Demographics and clinical differences between study groups were assessed using a chi-squared, Fisher's exact test, Student's t-test, or Mann-Whitney U test, as appropriate. The Pearson's $(r)$ correlation coefficient was used to determine linear correlation as appropriate. Association between variables was tested by simple regression analysis and coefficient of determination $\left(R^{2}\right)$ in case of non-linear correlation. A $P<0.05$ was considered as statistically significant.

\section{Table 1: Characteristics, hemodynamic and biological data on admission and fluid balance during the first 24 hours ( $n$} $=80$ )

\begin{tabular}{lc}
\hline Age (years) & $63 \pm 13$ \\
Male/female & $51 / 29$ \\
Body mass index & $24.8 \pm 4.8$ \\
APACHE II on admission & $22(18-28)$ \\
SOFA on admission & $8(5-10)$ \\
Medical/surgical & $55 / 25$ \\
COPD & $15(19 \%)$ \\
Diabetes & $21(26 \%)$ \\
Heart disease & $30(38 \%)$ \\
Chronic renal insufficiency & $7(9 \%)$ \\
Liver cirrhosis & $12(15 \%)$ \\
Immunosuppressive drugs & $26(33 \%)$ \\
Malignancy & $26(33 \%)$ \\
Community/hospital & $25 / 55$ \\
infections & \\
Severe sepsis/septic shock & $22 / 58$ \\
Mechanical ventilation & $57(71 \%)$ \\
Acute renal failure & $22(27 \%)$ \\
ICU stay (days) & $12(5-25)$ \\
Overall ICU mortality & $30(38 \%)$ \\
Fluid balance (mL/24 h) & $2559 \pm 2010$ \\
$\quad$ Mean IN (mL/24 h) & $4449 \pm 1877$ \\
\hline Mean OUT (mL/24 h) & $1890 \pm 1538$ \\
\hline Data are expressedas counts & \\
\hline
\end{tabular}

Data are expressed as counts (percentage), median (interquartile range) or mean \pm standard deviation.

APACHE, Acute Physiology and Chronic Health Evaluation; COPD, Chronic obstructive pulmonary disease; SOFA, Sequential Organ Failure Assessment.

\section{Results}

Patient characteristics

We enrolled 80 patients (mean age 63 years, 64\% male; Table 1) in the current study. Fifty-five (69\%) of the patients were medical admissions and 55 had a hospital or ICU-acquired infection; 58 (72\%) had septic shock. The median APACHE II score was 22 and the median SOFA score on admission was 8. Fifty-seven patients (71\%) were treated with mechanical ventilation; 22 patients (27\%) had acute renal failure. Overall ICU mortality was $38 \%$, mostly due to sepsis. Most infections were respiratory or abdominal and were microbiologically documented in 56 patients $(70 \%)$. Blood cultures were positive in 32 patients $(40 \%)$. Forty (50\%) cases of sepsis were secondary to Gram-negative bacilli, with 36 infections due to difficult-to-treat pathogens (P. aeruginosa $(\mathrm{n}=18)$; Enterobacter species $(\mathrm{n}=11)$; Citrobacter freundii, Hafnia alvei and Morganella morganii ( $\mathrm{n}=2$ for each); Serratia marcescens $(\mathrm{n}=1))$.

\section{Pharmacokinetic data}

Of the 80 patients, 16 were treated with meropenem, 18 with ceftazidime, 19 with cefepime, and 27 with piperacillin-tazobactam. The mean PK parameters for the four drugs are shown in Table 2. There was marked inter-individual variation in all PK parameters; Vd was increased for all four drugs when compared with healthy volunteers, with consequently a lower Cmax [see Additional file 1]. The median total CL was also reduced when compared with the median CL in healthy volunteers. The median percentage of $\mathrm{T}>4 \times$ MIC was $57 \%$ for meropenem, $45 \%$ for ceftazidime, $34 \%$ for cefepime, and $33 \%$ for piperacillin-tazobactam (Table 3). Thirteen patients had plasma concentrations less than four times the target MIC after only 90 minutes (ceftazidime $=1$; cefepime $=1$; piperacillin-tazobactam $=11)$. The number of patients who attained the target percentage $\mathrm{T}>4 \times \mathrm{MIC}$ was 12 of 16 for meropenem (75\%), 5 of 18 for ceftazidime (28\%), 3 of $19(16 \%)$ for cefepime, and 12 of 27 (44\%) for piperacillin-tazobactam.

Drug regimens were adapted because of renal impairment in 41 patients ( 6 treated with meropenem, 9 with ceftazidime, 12 with cefepime, and 14 with piperacillintazobactam). The $\mathrm{CrCl}$ was similar among the four groups (piperacillin-tazobactam 56 (ranges: 13 to 164) $\mathrm{mL} / \mathrm{min}$; meropenem 64 (22 to 134$) \mathrm{mL} / \mathrm{min}$; ceftazidime 58 (15 to 145$) \mathrm{mL} / \mathrm{min}$; cefepime 40 (13 to 150$) \mathrm{mL} / \mathrm{min}$ ). In patients with renal dysfunction $(\mathrm{CrCl}<50 \mathrm{~mL} / \mathrm{min}), 5$ of $6(83 \%)$ attained the target concentration for meropenem, 3 of 9 (33\%) for ceftazidime, 2 of 12 (17\%) for cefepime, and 10 of 14 (71\%) for piperacillin-tazobactam. For piperacillin-tazobactam, but not for the other antibiotics, patients with renal dysfunction had a significantly higher probability of having adequate drug concentra- 
Table 2: Pharmacokinetic parameters of the $\beta$-lactams

\begin{tabular}{|c|c|c|c|c|c|}
\hline & Vd (L/kg) & $C \max (\mu \mathrm{g} / \mathrm{mL})$ & AUC (mg.h/mL) & CL (mL/min.kg) & $t_{1 / 2}$ (hours) \\
\hline $\begin{array}{l}\text { Piperacillin- } \\
\text { tazobactam } \\
(n=27)\end{array}$ & $0.38(0.29-0.43)$ & $123(72-179)$ & 469 (196-896) & $2.02(1.33-4.26)$ & $2.58(1.51-3.84)$ \\
\hline $\begin{array}{l}\text { Meropenem } \\
\quad(n=16)\end{array}$ & $0.43(0.31-0.77)$ & $35(29-46)$ & $132(91-179)$ & $1.87(1.23-2.63)$ & $2.05(1.66-3.36)$ \\
\hline $\begin{array}{l}\text { Ceftazidime } \\
\quad(n=18)\end{array}$ & $0.48(0.36-0.71)$ & $63(48-78)$ & $522(392-634)$ & $0.89(0.63-1.34)$ & $5.84(4.13-7.39)$ \\
\hline $\begin{array}{c}\text { Cefepime } \\
(n=19)\end{array}$ & $0.36(0.33-0.44)$ & $68(51-86)$ & $310(234-422)$ & 1.26 (1.07-1.95) & $3.37(2.26-5.34)$ \\
\hline
\end{tabular}

Data are expressed as median [range].

$A U C$, area under the curve; $C L$, total clearance; $C$ max, peak concentration; $t_{1 / 2}$, elimination half-time; $V d$, volume of distribution.

tions than patients with normal renal function (10 of 14 vs. 2 of $13, P=0.03$ ). Calculating the probability of target $\mathrm{T}>4 \times$ MIC attainment for several MICs, values more than $90 \%$ were obtained for ceftazidime and piperacillintazobactam with MIC of $2 \mu \mathrm{g} / \mathrm{mL}$ or less and for cefepime and meropenem with MIC of $1 \mu \mathrm{g} / \mathrm{mL}$ or less (Table 4 ).

\section{Correlation with clinical variables}

No correlation was found between the T $>4 \times \mathrm{MIC}$ and any hemodynamic or clinical variable for any of the four drugs, including age, mechanical ventilation, APACHE II or SOFA score at admission, presence of shock, maximum dose of vasopressor agents or fluid balance. There was a significant correlation between $\mathrm{CrCl}$ at admission and CL for all drugs (data not shown).

\section{Discussion}

In this study, we show that current standard first doses of piperacillin-tazobactam, cefepime and ceftazidime are insufficient to maintain therapeutic serum concentrations greater than four times the MIC of P. aeruginosa in patients with severe sepsis and septic shock. Only with meropenem did a large percentage of patients achieve the bactericidal target of at least $40 \% \mathrm{~T}>4 \times \mathrm{MIC}$. Nevertheless, the probability of reaching the target concentration was greater than $90 \%$ only for MICs of $1 \mu \mathrm{g} / \mathrm{mL}$ or less for cefepime, and MICs of $2 \mu \mathrm{g} / \mathrm{mL}$ or less for ceftazidime and piperacillin-tazobactam, suggesting that, for all these drugs, insufficient drug concentrations are obtained for pathogens with higher MICs.

Broad spectrum $\beta$-lactams are active against most organisms recovered from ICU patients. Because of the emergence of multidrug-resistant strains and the lack of new antibiotics effective against Gram-negative bacteria [27], a more effective use of existing therapies is necessary. In vivo animal studies have demonstrated that $\beta$-lactams have a slow continuous kill characteristic that is almost entirely related to the time during which concentrations in tissue and serum exceed the MIC ( $\mathrm{T}>\mathrm{MIC})$ for the infecting organism $[28,29]$. The time above the MIC required for maximal $\beta$-lactam activity may differ depending on the drug as well as on the pathogen [24]. It has been proposed that, in the absence of post-antibiotic effects, the serum concentration of a $\beta$-lactam should exceed the MIC for the respective organism for $100 \%$ of the dosing interval [30]. However, experimental studies have suggested that maximum killing of bacteria occurs when $\beta$-lactam concentrations exceed four to five times the MIC of the infecting pathogen for extended periods

Table 3: Adequate concentrations of the four drugs, with regard to renal dysfunction

\begin{tabular}{|c|c|c|c|c|}
\hline & meropenem $(n=16)$ & ceftazidime $(n=18)$ & cefepime ( $n=19)$ & $\begin{array}{c}\text { piperacillin- } \\
\text { tazobactam }(n=27)\end{array}$ \\
\hline $\mathrm{T}>4 \times \mathrm{MIC}(\%)$ & $57(25-100)$ & $45(8-100)$ & $34(10-100)$ & $33(0-100)$ \\
\hline Adequate PK, n (\%) & $12(75)$ & $5(28)$ & $3(16)$ & $12(44)$ \\
\hline $\mathrm{CrCl}<50 \mathrm{~mL} / \mathrm{min}(\%)$ & $5 / 6(83)$ & $3 / 9(33)$ & $2 / 12(17)$ & $10 / 14(71)$ \\
\hline $\mathrm{CrCl}>50 \mathrm{~mL} / \mathrm{min}(\%)$ & $7 / 10(70)$ & $2 / 9(22)$ & $1 / 7(14)$ & $2 / 13(15) *$ \\
\hline
\end{tabular}

Data are expressed as counts (percentage) or median (range).

$\mathrm{CrCl}$, creatinine clearance; $\mathrm{MIC}$, minimal inhibitory concentration; $\mathrm{PK}$, pharmacokinetic.

* $P=0.03$ (vs. $\mathrm{CrCl}<50 \mathrm{~mL} / \mathrm{min}$ ). 


\begin{tabular}{|c|c|c|c|c|c|}
\hline \multirow[b]{2}{*}{ MIC $(\mu \mathrm{g} / \mathrm{mL})$} & \multirow[b]{2}{*}{$\begin{array}{c}\text { Target } \\
\text { concentration } \\
(\mu \mathrm{g} / \mathrm{mL})\end{array}$} & \multicolumn{4}{|c|}{ Adequate PK N (\%) } \\
\hline & & $\begin{array}{c}\text { meropenem } \\
(n=16)\end{array}$ & $\begin{array}{l}\text { ceftazidime } \\
(n=18)\end{array}$ & cefepime $(n=19)$ & $\begin{array}{c}\text { piperacillin- } \\
\text { tazobactam } \\
(\mathbf{n}=\mathbf{2 7})\end{array}$ \\
\hline 32 & 128 & 0 & 0 & 0 & $1(4)$ \\
\hline 16 & 64 & 0 & 0 & $1(5)$ & $12(44)$ \\
\hline 8 & 32 & 0 & $5(28)$ & $3(16)$ & $15(56)$ \\
\hline 4 & 16 & $3(18)$ & $14(78)$ & $7(36)$ & $21(78)$ \\
\hline 2 & 8 & $12(75)$ & $18(100)$ & $15(79)$ & $25(93)$ \\
\hline 1 & 4 & $15(94)$ & $18(100)$ & $17(90)$ & $27(100)$ \\
\hline 0.5 & 2 & $16(100)$ & $18(100)$ & $19(100)$ & $27(100)$ \\
\hline
\end{tabular}

Data are expressed as counts (percentage). In bold: MIC corresponding to European Committee on Antimicrobial Susceptibility Testing (EUCAST) clinical breakpoints for Pseudomonas aeruginosa.

MIC, minimal inhibitory concentration; PK, pharmacok inetics.

[31,32]. For the treatment of infections in humans, optimal $\beta$-lactam concentrations are still controversial. Clinical confirmation of the PK parameters needed for optimal $\beta$-lactam efficacy is limited because in several studies drug levels were not measured and the patients included had infections caused mostly by sensitive bacteria [33]. In patients treated with cephalosporins, $\mathrm{T}>\mathrm{MIC}$ of $100 \%$ was associated with greater clinical cure and bacteriological eradication than T > MIC less than 100\% [9]. However, the bactericidal activity of cephalosporins has also been shown to be optimal at drug concentrations of about four times the MIC [7]. Even if we preferred $4 \times$ MIC as PK end-point in this study, we did not have enough data to compare the efficacy of these two strategies in the human setting, and a prospective study evaluating the different $\beta$-lactams concentrations in the treatment of severe infections is necessary.

Studies on serum concentrations of broad-spectrum $\beta$ lactams have already reported that drug levels are insufficient in patients with severe infections. Cefepime $(2 \mathrm{~g}$ every 12 hours) concentrations were more than $70 \% \mathrm{~T}>$ $16 \mu \mathrm{g} / \mathrm{mL}$ in less than half the patients with sepsis [15] and were adequate only for MICs of $4 \mu \mathrm{g} / \mathrm{mL}$ in all eight patients suffering from post-operative infections [34]. Septic patients with normal renal function had serum cefepime and ceftazidime levels less than $32 \mu \mathrm{g} / \mathrm{mL}$ after a few hours in most cases [11,12]. Ceftazidime trough concentrations were below the median MIC of P. aeruginosa in more than half of the patients in another study [35]. In only one study, ceftazidime levels were above the MIC of the isolated pathogens for more than $90 \%$ of the time interval; however Pseudomonas was isolated in only 4 of 16 patients [16]. Finally, piperacillin concentrations were above therapeutic levels $(64 \mu \mathrm{g} / \mathrm{mL})$ for most of the time interval in patients with sepsis [36] or nosocomial pneumonia [37]. However, serum drug concentrations of meropenem were adequate in most of the patients. In severe infections associated with septicemia, mostly after cardiac surgery, meropenem had serum concentrations above $8 \mu \mathrm{g} / \mathrm{mL}$ for at least $50 \%$ of the time in patients with normal and those with reduced $\mathrm{CrCl}$ [38]. In patients with ventilator-associated pneumonia, mean $\mathrm{T}>$ $4 \times$ MIC for Pseudomonas was reported as $52 \%$ in one study [39] and $46 \%$ in another [17].

Nevertheless, most of these previous studies excluded severely ill patients with septic shock and those with an estimated $\mathrm{CrCl}$ limiting the generalization of their results to other populations of critically ill patients. The number of patients was also limited and analyses concerned only the steady-state of the disease. Finally, some of these studies used lower than recommended dosage regimens, which are associated with an increased mortality when susceptible pathogens with higher MICs are present $[40,41]$. Our study focused on a more severe population of patients, suffering from severe sepsis and septic shock, with higher mortality and morbidity rates than less severely ill ICU populations [42]. Importantly, we used recommended $\beta$-lactam regimens that have the greatest likelihood of achieving a bactericidal target in nosocomial pneumonia and bloodstream infections due to Gramnegative bacteria $[43,44]$. Finally, because antimicrobial treatment of sepsis is often initiated empirically, when pathogens and MICs are still unknown, we used as the target MIC the clinical breakpoint defined by EUCAST for $P$. aeruginosa, an organism that is commonly isolated in ICUs and associated with high mortality rates [25]. This strategy could then be extrapolated to other 'diffi- 
cult-to-treat' pathogens with high susceptibility breakpoints.

The consequences of these low antimicrobial levels may be more cases of therapeutic failure, higher medical costs and greater emergence of resistance [45]. Moreover, low plasma levels can contribute to lower than expected $\beta$ lactam concentrations in the extracellular [46], bronchial [47] or peritoneal fluid [48] with potentially reduced antimicrobial delivery to the target tissues. In view of these results, in septic patients, broad-spectrum $\beta$-lactams should be administered more frequently than suggested in non-septic patients, or with doses larger than standard regimens to optimize pathogen exposure to bactericidal concentrations of the drugs. Population modeling simulation showed that continuous or extended $\beta$-lactam infusions are required to obtain adequate serum concentrations [45]. However, clinical data that have shown a better outcome using this strategy have come just from retrospective studies in ICU populations with pneumonia $[49,50]$. Further studies are needed in ICU patients to assess the influence on morbidity and mortality of a strategy whereby antibiotic therapy is selected based on the optimal PK, especially in patients with sepsis and in infections caused by multiresistant pathogens.

Although a relation between the intensity of the septic process and PK abnormalities can be assumed, we did not find any relation between $\mathrm{T}>4 \times$ MIC and any demographic, clinical, hemodynamic or biological variables. This finding may be related to the fact that the PK analyses were performed during the early phase of sepsis. Also, as a first dose of antibiotic is largely influenced by $\mathrm{Vd}$, the increased distribution volume may play a key role in reducing antimicrobial concentrations in this setting whereas drug clearance remains the main determinant for drug concentrations at steady-state [13]. $\mathrm{CrCl}$ and drug CL showed good correlation, as elimination of the studied drugs is largely dependent on glomerular function $[11,38]$. Nevertheless, despite a regimen adapted to renal function, patients treated with piperacillin-tazobactam had a higher percentage of adequate concentrations when $\mathrm{CrCl}$ was below $50 \mathrm{~mL} / \mathrm{min}$. This finding may be related to the complex elimination of piperacillintazobactam, which includes biliary excretion [13]. Indeed, the hepatic metabolism of this drug is variable and difficult to measure and most studies on piperacillintazobactam PKs in patients with renal failure have included patients with normal hepatic function [51]. It is possible that, as severe sepsis is frequently associated with liver dysfunction, this may have contributed to greater than expected drug accumulation in some patients. Further studies are needed to evaluate the impact of renal and hepatic dysfunction on piperacillintazobactam regimens in critically ill patients.
Our study has some limitations. First, we evaluated the PK profile of $\beta$-lactams only during the first dose, and thus cannot make any statement with regard to subsequent doses. Vd may decrease during therapy when capillary leakage subsides and sepsis resolves [52]; in such circumstances, coupled with persistent renal dysfunction, standard $\beta$-lactam doses may be sufficient to achieve therapeutic concentrations. Second, as only free drug is the active moiety, it has been recommended that all PK/ pharmacodynamic indices should be referenced to the unbound (free) fraction of the drug, especially for some drugs such as piperacillin, which has 20 to $30 \%$ protein binding [53]. Third, the inadequate PK/pharmacodynamic indices observed in our study should be considered in relation to the empirical MIC target, and may be different with other susceptibility patterns (MIC distributions) of pathogens at individual institutions. Attention should therefore be paid to establish the MIC values of these pathogens in order to adapt dosage regimens. Also, $\mathrm{CrCl}$ was estimated using the Cockroft and Gault formula, which shows important limitations in predicting the real $\mathrm{CrCl}$ in ICU patients [54]. Finally, the four groups were heterogeneous and, therefore, the numbers may be too small to fully reflect the characteristics of the drugs in this setting. However, an important concern is the highly variable and unpredictable inter-individual PKs for cephalosporins and piperacillin and whether these drugs can be considered an appropriate agent to use as initial empirical therapy for critically ill patients with severe sepsis and septic shock, particularly in those with potentially less susceptible Gram-negative bacterial strains.

\section{Conclusions}

The treatment of infections in the critically ill patient remains a significant challenge for clinicians. Standard first doses of broad-spectrum $\beta$-lactams provided inadequate levels to achieve target serum concentrations for extended periods of time in critically ill patients with sepsis. Improved characterization of the pharmacodynamic properties of these antimicrobials may lead to revisions in recommendations on dosing in severe infections, especially in the early phase of severe sepsis and septic shock.

\section{Key messages}

- Recommended doses of piperacillin-tazobactam, cefepime and ceftazidime provided serum drug concentrations during the first 24 hours of treatment that were insufficient to cover $P$. aeruginosa and other less susceptible bacteria in patients suffering from severe sepsis and septic shock.

- Recommended doses of meropenem resulted in adequate concentrations to cover $P$. aeruginos $a$ and other less susceptible bacteria in $75 \%$ of patients. 
- In patients treated with piperacillin-tazobactam, renal dysfunction is associated with a better adequacy of drug concentrations compared with normal renal function.

- Therapeutic drug monitoring is necessary to optimize $\beta$-lactam concentrations as no clinical or biological variable can predict $\beta$-lactam concentrations in this population.

\section{Additional material}

Additional file 1 Three tables showing usual daily doses of antibiotics and dose adaptation to renal function, Minimum inhibitory concentrations (MICs) for Pseudomonas aeruginosa and Enterobacteriaceae according to European Committee on Antimicrobial Susceptibility Testing (EUCAST); and mean pharmacokinetic parameters in healthy volunteers.

\section{Abbreviations}

APACHE: acute physiology and health evaluation; AUC: area under the curve $\mathrm{CL}$ : total clearance; Cmax: peak concentration; $\mathrm{CrCl}$ : creatinine clearance; CV: coefficient of variation; EUCAST: European Committee on Antimicrobial Susceptibility Testing; LOD: limit of detection; LOQ: limit of quantification; MIC: minimum inhibitory concentration; PK: pharmacokinetics; SOFA: sequential organ failure assessment; $\mathrm{t}_{1 / 2}$ : elimination half-time; $\vee \mathrm{d}$ : volume of distribution.

\section{Competing interests}

FST, FJ, JLV, TD and PFL have received honoraria for lectures from Astra Zeneca. $J \mathrm{LV}$ is also on the speakers list of GlaxoSmithKline. The other authors declare that they have no competing interests.

\section{Authors' contributions}

FJ and PFL conceived the study protocol. FST, FJ, PFL, TD, XW, BL and HS participated in the design and coordination of the study. ID and PW performed the PK analyses. FST, PFL, DDB, JLV and FJ drafted the present manuscript. All authors read and approved the final manuscript.

\section{Acknowledgements}

We thank all the nurses and doctors who contributed to this study. The study was supported by grants from AstraZeneca, Wyeth Pharmaceuticals, GlaxoSmithKline Pharmaceuticals, and Bristol-Myers Squibb. These companies had no involvement in the writing of the paper or in the decision to submit for publication

\section{Author Details}

'Department of Intensive Care, Erasme Hospital, Université Libre de Bruxelles, route de Lennik 808, 1070 Bruxelles, Belgium, 2Department of Intensive Care, Cliniques Universitaires St-Luc, Ave Hippocrate 10, 1200 Brussels, Belgium, ${ }^{3}$ Department of Intensive Care, St-Pierre Hospital, Avenue Reine Fabiola 9, 1340 Ottignies, Belgium, ${ }^{4}$ Department of Intensive Care, Universitair Ziekenhuis Brusse, Laarbeeklaan 101, 1090 Brussel, Belgium, ${ }^{5}$ Department of Clinical Biochemistry and Pharmacokinetics, Cliniques Universitaires St-Luc, Ave Hippocrate 10, 1200 Brussels, Belgium and ${ }^{6}$ Department of Infectious Diseases, Erasme Hospital, Université Libre de Bruxelles, route de Lennik 808, 1070 Bruxelles, Belgium

Received: 24 March 2010 Revised: 25 May 2010

Accepted: 1 July 2010 Published: 1 July 2010

\section{References}

1. Vincent JL, Taccone F, Schmit X: Classification, incidence, and outcomes of sepsis and multiple organ failure. Contrib Nephrol 2007, 156:64-74.

2. Kollef MH, Sherman G, Ward S, Fraser VJ: Inadequate antimicrobial treatment of infections: a risk factor for hospital mortality among critically ill patients. Chest 1999, 115:462-474.

3. Zaragoza R, Artero A, Camarena JJ, Sancho S, Gonzalez R, Nogueira JM: The influence of inadequate empirical antimicrobial treatment on patients with bloodstream infections in an intensive care unit. Clin Microbiol Infect 2003, 9:412-418.

4. Roberts JA, Roberts MS, Robertson TA, Dalley AJ, Lipman J: Piperacillin penetration into tissue of critically ill patients with sepsis--bolus versus continuous administration? Crit Care Med 2009, 37:926-933.

5. Dellinger RP, Levy MM, Carlet JM, Bion J, Parker MM, Jaeschke R, Reinhart K, Angus DC, Brun-Buisson C, Beale R, Calandra T, Dhainaut JF, Gerlach H, Harvey M, Marini JJ, Marshall J, Ranieri M, Ramsay G, Sevransky J, Thompson BT, Townsend S, Vender JS, Zimmerman JL, Vincent JL: Surviving Sepsis Campaign: international guidelines for management of severe sepsis and septic shock: 2008. Crit Care Med 2008, 36:296-327.

6. Pinder M, Bellomo R, Lipman J: Pharmacological principles of antibiotic prescription in the critically ill. Anaesth Intensive Care 2002, 30:134-144.

7. Tam VH, McKinnon PS, Akins RL, Rybak MJ, Drusano GL: Pharmacodynamics of cefepime in patients with Gram-negative infections. J Antimicrob Chemother 2002, 50:425-428.

8. Thalhammer F, Traunmuller F, el MI, Frass M, Hollenstein UM, Locker GJ, Stoiser B, Staudinger T, Thalhammer-Scherrer R, Burgmann H: Continuous infusion versus intermittent administration of meropenem in critically ill patients. J Antimicrob Chemother 1999, 43:523-527.

9. Nicolau DP, Onyeji CO, Zhong M, Tessier PR, Banevicius MA, Nightingale $\mathrm{CH}$ : Pharmacodynamic assessment of cefprozil against Streptococcus pneumoniae: implications for breakpoint determinations. Antimicrob Agents Chemother 2000, 44:1291-1295.

10. McKinnon PS, Paladino JA, Schentag JJ: Evaluation of area under the inhibitory curve (AUIC) and time above the minimum inhibitory concentration ( $\mathrm{T}>\mathrm{MIC}$ ) as predictors of outcome for cefepime and ceftazidime in serious bacterial infections. Int J Antimicrob Agents 2008 , 31:345-351

11. Lipman J, Gomersall CD, Gin T, Joynt GM, Young RJ: Continuous infusion ceftazidime in intensive care: a randomized controlled trial. Antimicrob Chemother 1999, 43:309-311.

12. Lipman J, Wallis SC, Rickard C: Low plasma cefepime levels in critically ill septic patients: pharmacokinetic modeling indicates improved troughs with revised dosing. Antimicrob Agents Chemother 1999 43:2559-2561

13. Roberts JA, Lipman J: Pharmacokinetic issues for antibiotics in the critically ill patient. Crit Care Med 2009, 37:840-851.

14. Pea F, Viale P, Furlanut M: Antimicrobial therapy in critically ill patients: a review of pathophysiological conditions responsible for altered disposition and pharmacokinetic variability. Clin Pharmacokinet 2005, 44:1009-1034.

15. Ambrose PG, Owens RC Jr, Garvey MJ, Jones RN: Pharmacodynamic considerations in the treatment of moderate to severe pseudomonal infections with cefepime. J Antimicrob Chemother 2002, 49:445-453.

16. Benko AS, Cappelletty DM, Kruse JA, Rybak MJ: Continuous infusion versus intermittent administration of ceftazidime in critically ill patients with suspected gram-negative infections. Antimicrob Agents Chemother 1996, 40:691-695.

17. Jaruratanasirikul S, Sriwiriyajan S, Punyo J: Comparison of the pharmacodynamics of meropenem in patients with ventilatorassociated pneumonia following administration by 3-hour infusion or bolus injection. Antimicrob Agents Chemother 2005, 49:1337-1339.

18. Levy MM, Fink MP, Marshall JC, Abraham E, Angus D, Cook D, Cohen J, Opal SM, Vincent JL, Ramsay G: 2001 SCCM/ESICM/ACCP/ATS/SIS International Sepsis Definitions Conference. Crit Care Med 2003 31:1250-1256.

19. Knaus WA, Draper EA, Wagner DP, Zimmerman JE: APACHE II: a severity of disease classification system. Crit Care Med 1985, 13:818-829.

20. Vincent JL, Moreno R, Takala J, Willatts S, De Mendonca A, Bruining H, Reinhart CK, Suter PM, Thijs LG: The SOFA (Sepsis-related Organ Failure Assessment) score to describe organ dysfunction/failure. On behalf of the Working Group on Sepsis-Related Problems of the European Society of Intensive Care Medicine. Intensive Care Med 1996, 22:707-710.

21. Cockcroft DW, Gault MH: Prediction of creatinine clearance from serum creatinine. Nephron 1976, 16:31-41

22. Buck C, Bertram N, Ackermann T, Sauerbruch $T$, Derendorf $H$, Paar WD: Pharmacokinetics of piperacillin-tazobactam: intermittent dosing versus continuous infusion. Int J Antimicrob Agents 2005, 25:62-67.

23. Delattre IK, Musuamba FT, Verbeeck RK, Dugernier T, Spapen H, Laterre PF, Wittebole X, Cumps J, Taccone FS, Vincent JL, Jacobs F, Wallemacq PE: Empirical models for dosage optimization of four beta-lactams in 
critically ill septic patients based on therapeutic drug monitoring of amikacin. Clin Biochem 2010, 43:589-598.

24. Drusano GL: Antimicrobial pharmacodynamics: critical interactions of 'bug and drug'. Nat Rev Microbiol 2004, 2:289-300.

25. Shorr AF: Review of studies of the impact on Gram-negative bacterial resistance on outcomes in the intensive care unit. Crit Care Med 2009, 37:1463-1469

26. Clinical breakpoints - bacteria [http://www.eucast.org/fileadmin/src/ media/PDFs/EUCAST files/Disk test documents/ EUCAST breakpoints V1.0 20091221.pdf

27. Falagas ME, Kopterides P: Old antibiotics for infections in critically ill patients. Curr Opin Crit Care 2007, 13:592-597.

28. Andes D, Craig WA: In vivo activities of amoxicillin and amoxicillinclavulanate against Streptococcus pneumoniae: application to breakpoint determinations. Antimicrob Agents Chemother 1998, 42:2375-2379

29. Mouton JW, Punt N: Use of the $\mathrm{t}>$ MIC to choose between different dosing regimens of beta-lactam antibiotics. J Antimicrob Chemother 2001, 47:500-501.

30. Turnidge JD: The pharmacodynamics of beta-lactams. Clin Infect Dis 1998, 27:10-22.

31. Williamson R, Tomasz A: Inhibition of cell wall synthesis and acylation of the penicillin binding proteins during prolonged exposure of growing Streptococcus pneumoniae to benzylpenicillin. Eur J Biochem 1985, 151:475-483.

32. Craig WA, Redington J, Ebert SC: Pharmacodynamics of amikacin in vitro and in mouse thigh and lung infections. J Antimicrob Chemother 1991, 27(Suppl C):29-40.

33. Angus BJ, Smith MD, Suputtamongkol Y, Mattie H, Walsh AL, Wuthiekanun V, Chaowagul W, White NJ: Pharmacokineticpharmacodynamic evaluation of ceftazidime continuous infusion vs intermittent bolus injection in septicaemic melioidosis. $\mathrm{Br} J \mathrm{Clin}$ Pharmacol 2000, 50:184-191

34. Ikawa K, Morikawa N, Hayato S, Ikeda K, Ohge H, Sueda T: Pharmacokinetic and pharmacodynamic profiling of cefepime in plasma and peritoneal fluid of abdominal surgery patients. Int $\mathrm{J}$ Antimicrob Agents 2007, 30:270-273.

35. Young RJ, Lipman J, Gin T, Gomersall CD, Joynt GM, Oh TE: Intermittent bolus dosing of ceftazidime in critically ill patients. J Antimicrob Chemother 1997, 40:269-273.

36. Roberts JA, Kirkpatrick CM, Roberts MS, Dalley AJ, Lipman J: First-dose and steady-state population pharmacokinetics and pharmacodynamics of piperacillin by continuous or intermittent dosing in critically ill patients with sepsis. Int J Antimicrob Agents 2010 35:156-163.

37. Boselli E, Breilh D, Cannesson M, Xuereb F, Rimmele T, Chassard D, Saux MC, Allaouchiche B: Steady-state plasma and intrapulmonary concentrations of piperacillin/tazobactam $4 \mathrm{~g} / 0.5 \mathrm{~g}$ administered to critically ill patients with severe nosocomial pneumonia. Intensive Care Med 2004, 30:976-979.

38. Kitzes-Cohen R, Farin D, Piva G, Myttenaere-Bursztein SA: Pharmacokinetics and pharmacodynamics of meropenem in critically ill patients. Int J Antimicrob Agents 2002, 19:105-110.

39. de Stoppelaar F, Stolk L, van Tiel F, Beysens A, van der GS, de Leeuw P: Meropenem pharmacokinetics and pharmacodynamics in patients with ventilator-associated pneumonia. J Antimicrob Chemother 2000 46:150-151

40. Bhat SV, Peleg AY, Lodise TP Jr, Shutt KA, Capitano B, Potoski BA, Paterson $D L$ : Failure of current cefepime breakpoints to predict clinical outcomes of bacteremia caused by gram-negative organisms. Antimicrob Agents Chemother 2007, 51:4390-4395

41. Tam VH, Gamez EA, Weston JS, Gerard LN, Larocco MT, Caeiro JP, Gentry LO, Garey KW: Outcomes of bacteremia due to Pseudomonas aeruginosa with reduced susceptibility to piperacillin-tazobactam: implications on the appropriateness of the resistance breakpoint. Clin Infect Dis 2008, 46:862-867.

42. Vincent JL, Sakr Y, Sprung CL, Ranieri VM, Reinhart K, Gerlach H, Moreno R, Carlet J, Le Gall JR, Payen D: Sepsis in European intensive care units: results of the SOAP study. Crit Care Med 2006, 34:344-353.

43. Sun HK, Kuti JL, Nicolau DP: Pharmacodynamics of antimicrobials for the empirical treatment of nosocomial pneumonia: a report from the OPTAMA Program. Crit Care Med 2005, 33:2222-2227.
44. Maglio D, Kuti JL, Nicolau DP: Simulation of antibiotic pharmacodynamic exposure for the empiric treatment of nosocomial bloodstream infections: a report from the OPTAMA program. Clin The 2005, 27:1032-1042.

45. Scaglione F, Paraboni L: Pharmacokinetics/pharmacodynamics of antibacterials in the Intensive Care Unit: setting appropriate dosing regimens. Int J Antimicrob Agents 2008, 32:294-301.

46. Zeitlinger MA, Erovic BM, Sauermann R, Georgopoulos A, Muller M, Joukhadar C: Plasma concentrations might lead to overestimation of target site activity of piperacillin in patients with sepsis. J Antimicrob Chemother 2005, 56:703-708.

47. Klekner A, Bagyi K, Bognar L, Gaspar A, Andrasi M, Szabo J: Effectiveness of cephalosporins in the sputum of patients with nosocomial bronchopneumonia. J Clin Microbiol 2006, 44:3418-3421.

48. Wise R, Logan M, Cooper M, Ashby JP, Andrews JM: Meropenem pharmacokinetics and penetration into an inflammatory exudate. Antimicrob Agents Chemother 1990, 34:1515-1517.

49. Lodise TP Jr, Lomaestro B, Drusano GL: Piperacillin-tazobactam for Pseudomonas aeruginosa infection: clinical implications of an extended-infusion dosing strategy. Clin Infect Dis 2007, 44:357-363.

50. Lorente L, Jimenez A, Palmero S, Jimenez JJ, Iribarren JL, Santana M, Martin MM, Mora ML: Comparison of clinical cure rates in adults with ventilator-associated pneumonia treated with intravenous ceftazidime administered by continuous or intermittent infusion: a retrospective, nonrandomized, open-label, historical chart review. Clin Ther 2007, 29:2433-2439

51. Thompson MI, Russo ME, Matsen JM, Atkin-Thor E: Piperacillin pharmacokinetics in subjects with chronic renal failure. Antimicrob Agents Chemother 1981, 19:450-453.

52. Triginer C, Izquierdo I, Fernandez R, Rello J, Torrent J, Benito S, Net A: Gentamicin volume of distribution in critically ill septic patients. Intensive Care Med 1990, 16:303-306.

53. Muller M, Haag O, Burgdorff T, Georgopoulos A, Weninger W, Jansen B, Stanek G, Pehamberger H, Agneter E, Eichler HG: Characterization of peripheral-compartment kinetics of antibiotics by in vivo microdialysis in humans. Antimicrob Agents Chemother 1996, 40:2703-2709.

54. Martin JH, Fay MF, Udy A, Roberts J, Kirkpatrick C, Ungerer J, Lipman J: Pitfalls of using estimations of glomerular filtration rate in an intensive care population. Intern Med $J 2010$ in press.

doi: $10.1186 /$ cc9091

Cite this article as: Taccone et al., Insufficient ?-lactam concentrations in the early phase of severe sepsis and septic shock Critical Care 2010, 14:R126

\section{Submit your next manuscript to BioMed Centra and take full advantage of:}

- Convenient online submission

- Thorough peer review

- No space constraints or color figure charges

- Immediate publication on acceptance

- Inclusion in PubMed, CAS, Scopus and Google Scholar

- Research which is freely available for redistribution 